British Journal of Nutrition (2012), 108, 1800-1809

doi:10.1017/S0007114512000128

(C) The Authors 2012. The online version of this article is published within an Open Access environment subject to the conditions of the Creative Commons Attribution-NonCommercial-ShareAlike licence $<$ http://creativecommons.org/licenses/by-nc-sa/2.5/ $>$. The written permission of Cambridge University Press must be obtained for commercial re-use.

\title{
Safety evaluation of vitamin A in growing dogs
}

\author{
Penelope J. Morris ${ }^{1 *}$, Carina Salt ${ }^{1}$, Jens Raila ${ }^{2}$, Thomas Brenten ${ }^{3}$, Barbara Kohn ${ }^{4}$, Florian J. Schweigert ${ }^{2}$ \\ and Jürgen Zentek ${ }^{5}$ \\ ${ }^{1}$ WALTHAM ${ }^{\circledR}$ Centre for Pet Nutrition, Freeby Lane, Waltham on the Wolds, Melton Mowbray, Leicestershire, UK \\ ${ }^{2}$ Institute of Nutritional Science, University of Potsdam, Arthur-Scheunert-Allee 114-116, D-14558 Bergholz-Rehbrücke, \\ Germany \\ ${ }^{3}$ Mars GmbH, Eitzer Straße 215, 27283 Verden, Germany \\ ${ }^{4}$ Department of Veterinary Medicine, Clinic of Small Animals, Freie Universität Berlin, Oertzenweg 19b, 14163 Berlin, \\ Germany \\ ${ }^{5}$ Department of Veterinary Medicine, Institute of Animal Nutrition, Freie Universität Berlin, Königin-Luise-Straße 49, 14195 \\ Berlin, Germany
}

(Submitted 4 August 2011 - Final revision received 20 December 2011 - Accepted 6 January 2012 - First published online 1 March 2012)

\begin{abstract}
The safe upper limit for inclusion of vitamin A in complete diets for growing dogs is uncertain, with the result that current recommendations range from 5.24 to $104.80 \mu \mathrm{mol}$ retinol (5000 to $100000 \mathrm{IU}$ vitamin A)/4184 kJ ( $1000 \mathrm{kcal}$ ) metabolisable energy (ME). The aim of the present study was to determine the effect of feeding four concentrations of vitamin A to puppies from weaning until 1 year of age. A total of forty-nine puppies, of two breeds, Labrador Retriever and Miniature Schnauzer, were randomly assigned to one of four treatment groups. Following weaning at 8 weeks of age, puppies were fed a complete food supplemented with retinyl acetate diluted in vegetable oil and fed at $1 \mathrm{ml} \mathrm{oil} / 100 \mathrm{~g}$ diet to achieve an intake of 5.24, 13·10, 78.60 and 104.80 $\mu \mathrm{mol}$ retinol $(5000,12500,75000$ and $100000 \mathrm{IU}$ vitamin A)/4184 kJ (1000 kcal) ME. Fasted blood and urine samples were collected at 8, 10, 12, 14, 16, 20, 26, 36 and 52 weeks of age and analysed for markers of vitamin A metabolism and markers of safety including haematological and biochemical variables, bone-specific alkaline phosphatase, cross-linked carboxyterminal telopeptides of type I collagen and dual-energy X-ray absorptiometry. Clinical examinations were conducted every 4 weeks. Data were analysed by means of a mixed model analysis with Bonferroni corrections for multiple endpoints. There was no effect of vitamin A concentration on any of the parameters, with the exception of total serum retinyl esters, and no effect of dose on the number, type and duration of adverse events. We therefore propose that $104.80 \mu \mathrm{mol}$ retinol (100000 IU vitamin A)/4184 kJ (1000 kcal) is a suitable safe upper limit for use in the formulation of diets designed for puppy growth.
\end{abstract}

Key words: Puppies: Dogs: Retinol: Retinyl esters: Vitamin A

Vitamin A is an essential fat-soluble vitamin that has functions supporting vision, bone growth, reproduction, cellular differentiation and immune response in $\operatorname{dogs}^{(1)}$. The dog, unlike non-carnivorous species such as humans or rodents, transports vitamin $\mathrm{A}$ in the plasma predominantly in the form of retinyl esters, in both adequate and vitamin A-deprived states ${ }^{(2)}$. In human subjects, retinyl esters are only detected in the plasma in cases of intoxication or following a vitamin A-rich meal ${ }^{(3)}$. The concentrations of retinol found in dog serum are unaffected by dietary vitamin A intake, whereas the concentrations of serum retinyl esters have been shown to parallel the concentrations of vitamin A in the $\operatorname{diet}^{(3)}$. In the dog, excess vitamin $\mathrm{A}$ is stored in esterified form in lipid droplets contained within the hepatic stellate cells as well as the kidneys ${ }^{(4)}$. In addition to the unusual mechanism of vitamin A transport, dogs, unlike humans ${ }^{(5)}$, excrete vitamin $\mathrm{A}$ in the urine $^{(6)}$ as both retinol and retinyl esters ${ }^{(7)}$.

As a result of the species differences in metabolism and excretion, data from other species cannot be used to establish a dietary safe upper limit for retinol inclusion in the diets of growing dogs. Some studies in dogs, however, do exist. In growing dogs (10-12 months of age), prolonged activated prothrombin time, although not to levels outwith the

Abbreviations: BMD, bone mineral density; CTx, carboxyterminal telopeptides of type I collagen; DXA, dual-energy X-ray absorptiometry; FEDIAF, Federation Européenne de l'Industrie des Ailments pour Animaux Familiers; LR, Labrador Retriever; ME, metabolisable energy; MS, Miniature Schnauzer. 
reference range, and elevated retinol binding protein concentrations have been reported following feeding a diet containing $131.00 \mu \mathrm{mol}$ retinol (125000 IU vitamin A)/ $4184 \mathrm{~kJ}$ (1000 kcal) metabolisable energy (ME) for a period of 26 weeks potentially resulting from an interaction with vitamin $\mathrm{K}^{(1)}$. Exceptionally high dietary intakes $(>576.42 \mu \mathrm{mol}$ retinol (550000 IU vitamin A)/4184 kJ (1000 kcal) ME) were associated with severe side effects including reduced energy intake, reduced growth rates, pain responses in the carpal and tarsal joints as well as abnormal bone development and premature closure of the epiphyseal plate ${ }^{(8-10)}$. These adverse effects are potentially a result of interactions with vitamin $D$, as one study reported a reduction in the severity of effects when retinol was CO-administered with vitamins $D$ and $E^{(11)}$. Much lower concentrations $(10.48 \mu \mathrm{mol}$ retinol (10000 IU vitamin A) $\mathrm{kg}$ /body weight) fed to three Cocker Spaniels from weaning to 10 months of age had no apparent adverse effects ${ }^{(12)}$.

The lack of published studies involving retinol concentrations above $10.48 \mu \mathrm{mol}$ retinol (10000 IU vitamin A)/kg body weight that have not observed adverse effects may explain the disparity in recommendations among key nutrition authorities. The National Research Council ${ }^{(13)}$ recommends a safe upper limit of $13 \cdot 10 \mu \mathrm{mol}$ retinol (12500 IU vitamin A)/ $4184 \mathrm{~kJ}(1000 \mathrm{kcal})$ for growing dogs, the American Association of Feed Control Officials ${ }^{(14)}$ recommends $74.86 \mu \mathrm{mol}$ retinol (71 429 IU vitamin A)/4184 kJ (1000 kcal) and the Federation Européenne de l'Industrie des Ailments pour Animaux Familiers (FEDIAF) ${ }^{(15)}$ recommends $104 \cdot 80 \mu \mathrm{mol}$ retinol (10000 IU vitamin A)/4184 kJ (1000 kcal). The purpose of the present study was to examine the effect on puppies of feeding four concentrations of vitamin A from weaning until 12 months of age. The hypothesis tested was that feeding dietary retinol concentrations up to $104.80 \mu \mathrm{mol}$ retinol (10 $000 \mathrm{IU}$ vitamin A)/4184 kJ (1000 kcal) to puppies during growth does not result in a statistically significant change in biomarkers associated with health.

\section{Experimental methods}

The research protocol was evaluated and approved by the WALTHAM $^{\circledR}$ Internal Ethics Committee. The study was a randomised, blinded, parallel design. A total of forty-nine puppies, from eight litters, born at the WALTHAM Centre for Pet Nutrition were entered into the study. The puppies were of two breeds, Labrador Retrievers (LR) and Miniature Schnauzers (MS). Dogs were housed in litter groups with their mother until 8 weeks of age and subsequently in pairs, in purposebuilt, environmentally enriched kennels with free access to outdoor areas. The puppies could interact with other dogs in paddock groups, and all puppies participated daily in supervised group and individual exercise, training and socialisation. The puppies were habituated to all procedures from 4 weeks of age.

\section{Diet and feeding}

The base diet was a standard dry commercial recipe (Perfect Fit Junior; Mars GmbH) compliant with FEDIAF 2008 recommendations $^{(15)}$ for growth and reproduction (Table 1).
Table 1. Nutrient composition of the base diet ${ }^{\star}$

(Mean values and standard deviations, $n 10$ batches of diet)

\begin{tabular}{|c|c|c|}
\hline Nutrient & Mean (units/kg) & SD \\
\hline PME (kJ) & 16640 & 582 \\
\hline Protein (g) & 302 & 6 \\
\hline Fat $(g)$ & 169 & 4 \\
\hline Ash (g) & 69 & 3 \\
\hline $\mathrm{N}$-free extract $(\mathrm{g})$ & 364 & 20 \\
\hline Crude fibre $(\mathrm{g})$ & 23 & 17 \\
\hline Linoleic acid (g) & $25 \cdot 0$ & 0.4 \\
\hline$\alpha$-Linolenic acid (g) & 1.7 & 0.1 \\
\hline EPA and DHA (g) & 0.9 & 0.1 \\
\hline $\mathrm{Ca}(\mathrm{g})$ & $13 \cdot 1$ & $1 \cdot 1$ \\
\hline$P(g)$ & $9 \cdot 2$ & 0.7 \\
\hline Ca:P & 1.4 & 0.1 \\
\hline $\mathrm{Na}(\mathrm{g})$ & 5.4 & 0.7 \\
\hline $\mathrm{K}(\mathrm{g})$ & $6 \cdot 0$ & 0.9 \\
\hline $\mathrm{Mg}(\mathrm{g})$ & 0.86 & 0.1 \\
\hline $\mathrm{Fe}(\mathrm{mg})$ & 126 & 14 \\
\hline $\mathrm{Cu}(\mathrm{mg})$ & 12 & 2 \\
\hline $\mathrm{Mn}(\mathrm{mg})$ & 88 & 10 \\
\hline $\mathrm{Zn}(\mathrm{mg})$ & 142 & 34 \\
\hline $\mathrm{I}(\mathrm{mg})$ & $1 \cdot 3$ & 0.3 \\
\hline $\operatorname{Se}(\mu \mathrm{g})$ & 360 & 130 \\
\hline Chloride (g) & $1 \cdot 1$ & 0.1 \\
\hline Retinol $(\mu \mathrm{g})$ & 5870 & 1047 \\
\hline Cholecalciferol $(\mu \mathrm{g})$ & 39.5 & 7.6 \\
\hline$\alpha$-Tocopherol (mg) & 529 & 204 \\
\hline Thiamin (mg) & 2.5 & 0.6 \\
\hline Riboflavin (mg) & $20 \cdot 7$ & $5 \cdot 4$ \\
\hline Niacin (mg) & 139.4 & 44.4 \\
\hline Pyridoxine (mg) & $10 \cdot 0$ & 0.8 \\
\hline Pantothenic acid (mg) & 61 & 25 \\
\hline Folic acid (mg) & $1 \cdot 12$ & 0.8 \\
\hline Cobalamin (mg) & 0.13 & 0.1 \\
\hline Choline (mg) & 1222 & 689 \\
\hline $\operatorname{Arg}(\mathrm{g})$ & $17 \cdot 6$ & 0.2 \\
\hline His (g) & $5 \cdot 7$ & 0.5 \\
\hline Ile (g) & $10 \cdot 3$ & 0.1 \\
\hline Leu (g) & $24 \cdot 1$ & $2 \cdot 5$ \\
\hline Lys (g) & $13 \cdot 3$ & 0.94 \\
\hline Met $(\mathrm{g})$ & $5 \cdot 6$ & 0.3 \\
\hline Met + cystine $(\mathrm{g})$ & 9.5 & 0.4 \\
\hline Phe (g) & 9.5 & 0.8 \\
\hline Phe + Tyr (g) & $21 \cdot 7$ & $2 \cdot 7$ \\
\hline Thr (g) & $9 \cdot 1$ & 0.4 \\
\hline Val (g) & $11 \cdot 0$ & 0.9 \\
\hline
\end{tabular}

PME, predicted metabolisable energy.

${ }^{*}$ PME calculated according to the National Research Council ${ }^{(13)}$.

For each group, ten batches of the diet were used throughout the study. The predicted ME content of the diet was calculated according to the National Research Council ${ }^{(13)}$.

The maternal bitch was fed the base diet throughout lactation until the puppies were fully weaned to the base diet at 6 weeks of age. For $7 \mathrm{~d}$ following weaning (week 6-7), the puppies were group fed the base diet three times daily. For the following $7 \mathrm{~d}$ (week 7-8), the puppies were individually fed the base diet for three, $1 \mathrm{~h}$ periods daily. Feeding amounts were calculated from amounts consumed during the previous week and adjusted weekly for the remainder of the study with the aim of maintaining puppies on standard growth curves with ideal body condition scores ${ }^{(16,17)}$. At 8 weeks of age, puppies were randomised within litter, to one of four dietary concentrations of vitamin A, namely: group A $5.24 \mu \mathrm{mol}$ retinol (5000 IU vitamin A)/4184kJ 
(1000 kcal) ME; group B $13 \cdot 10 \mu \mathrm{mol}$ retinol (12500 IU vitamin A) $/ 4184 \mathrm{~kJ}$ (1000 kcal) ME; group C $78.60 \mu \mathrm{mol}$ retinol $(75000$ IU vitamin A)/4184 kJ (1000 kcal) ME; group D $104.80 \mu \mathrm{mol}$ retinol (100000 IU vitamin A) $/ 4184 \mathrm{~kJ}$ ( $1000 \mathrm{kcal})$ ME. For the following 18 weeks (week 8-26), the puppies were offered their respective diet for a period of $45 \mathrm{~min}$ at 08.30 , 12.30 and 15.30 hours. For the final 26 weeks of study (week 26-52), the puppies were offered their daily ration in two meals at 08.30 and 15.30 hours. Puppies were given free access to drinking-water at all times.

\section{Vitamin A supplementation}

The base diet was supplemented to achieve the required level of vitamin A by the addition of retinyl acetate (DSM Nutritional Products Limited) diluted to the required concentration in vegetable oil. Stock solutions were prepared weekly for each group according to the manufacturer's instructions and were refrigerated in light-proof bottles under $\mathrm{N}_{2}$ until required. Individual supplements were prepared in $1 \mathrm{ml}$ syringes from the stock solution and kept refrigerated in light-proof containers before being added to the diet at a ratio of $1 \mathrm{ml}$ supplement/ $100 \mathrm{~g}$ of diet immediately before feeding and mixed thoroughly. A $1 \mathrm{ml}$ aliquot of each stock solution was analysed within $48 \mathrm{~h}$ of the stock solution preparation for retinyl acetate concentrations using modified gradient reversed-phase HPLC analysis ${ }^{(3)}$ to allow for the calculation of actual vitamin A intake.

\section{Measurement of food intake and body weight}

Food intake was recorded immediately following each meal as the difference between the mass of food presented and the mass of food returned (Sartorius UK Limited). Body weight was recorded weekly using calibrated scales (Sartorius UK Limited) immediately before the first meal of the day. Although not fully validated in puppies, the body condition score was conducted weekly (WALTHAM S.H.A.P.E. guide ${ }^{(17)}$ ), immediately before feeding.

\section{Blood sample analysis}

A $2.8 \mathrm{ml}$ blood sample was taken from a jugular vein following an overnight fast of at least $16 \mathrm{~h}$ at week 8 , before dietary supplementation, and at weeks 10, 12, 14, 16, 20, 26, 35 and 52. Blood samples were collected into a single syringe and immediately distributed between tubes containing either tripotassium EDTA, lithium heparin or no anticoagulant.

For biochemical analysis, $0.5 \mathrm{ml}$ of blood were deposited into a tube containing lithium heparin as an anticoagulant. The tube was mixed gently for $10 \mathrm{~s}$ before being stored on ice for a maximum of $30 \mathrm{~min}$. The sample was then centrifuged at $2000 \mathrm{~g}$ for $10 \mathrm{~min}$ at $4^{\circ} \mathrm{C}$. The resultant plasma was pipetted into an AU400 sample cup before automated colorimetric analysis (Olympus AU400; Olympus, Inc.) for concentrations of total protein, albumin, alkaline phosphatase, aspartate aminotransferase, alanine aminotransferase, total cholesterol, urea, creatinine, $\mathrm{Ca}$, phosphate, TAG, glutamate dehydrogenase and total bile acids.
For haematological analysis, a $0 \cdot 2 \mathrm{ml}$ blood sample was deposited into a tube containing tripotassium EDTA as an anticoagulant. This was gently mixed on a roller for $10 \mathrm{~min}$ at room temperature before automated analysis for leucocyte count, erythrocyte count, $\mathrm{Hb}$ concentration, haematocrit, platelet count, mean corpuscular volume, mean corpuscular $\mathrm{Hb}$, mean corpuscular $\mathrm{Hb}$ concentration, number and percentage of lymphocytes, monocytes and granulocytes (ABC, Scil Vet).

For retinol and retinyl esters, the remaining $2 \cdot 1 \mathrm{ml}$ blood sample was deposited into a light-proof tube containing no anticoagulant. The tube was placed in an upright position for $90 \mathrm{~min}$ at room temperature, to allow clot formation, before centrifugation at $2000 \boldsymbol{g}$ for $10 \mathrm{~min}$ at room temperature. The resultant serum was pipetted into $1.5 \mathrm{ml}$ light-proof Eppendorf tubes, frozen at $-80^{\circ} \mathrm{C}$, shipped overnight on ice and stored at $-80^{\circ} \mathrm{C}$ for a maximum of $30 \mathrm{~d}$ before analysis using modified gradient reversed-phase HPLC analysis, as described elsewhere $^{(3)}$, to determine the concentrations of retinol, retinyl oleate, retinyl stearate and retinyl palmitate. The total retinyl ester concentration was calculated as the sum of retinyl oleate, retinyl stearate and retinyl palmitate concentrations.

For bone turnover assessment, the remainder of the serum sample used for retinol and retinyl ester analyses was used to measure cross-linked carboxyterminal telopeptides of type I collagen (CTx) concentrations, as an indicator of bone resorption, using a commercial ELISA (Serum CrossLaps ELISA; IDS). Serum bone-specific alkaline phosphatase activity, as an indicator of osteoblastic activity, was measured with a commercial ELISA assay (Osteomedical).

\section{Urine samples}

At $1 \mathrm{~d}$ before blood sampling, a $1.2 \mathrm{ml}$ urine sample was collected following a $16 \mathrm{~h}$ fast between the hours of 08.00 and 10.00 by a free-catch method. If a urine sample could not be obtained on the first day of sampling, the process was repeated on the following day before blood sampling. The samples were placed in light-proof Eppendorf tubes, and then stored, shipped and analysed for retinol and retinyl esters as described above.

\section{Bone mineral density and bone mineral content}

Bone mineral density (BMD) was assessed at 26 and 52 weeks of age by means of dual-energy X-ray absorptiometry (DXA, total body software package, Lunar Hologic QDR-1000W; GE Healthcare). Dogs were sedated following a minimum $16 \mathrm{~h}$ fast, with a combination of Torbugesic $(0.3 \mathrm{mg} / \mathrm{kg}$; Pfizer Animal Health), Medetomidine (MS: $20 \mu \mathrm{g} / \mathrm{kg}$, LR: $5 \mu \mathrm{g} / \mathrm{kg}$; Pfizer Animal Health) and Midazolam (MS: 0.25 mg/kg, LR: 0.20 mg/ $\mathrm{kg}$; Roche Limited), and reversed with Atipamezole (0.1 mg/ kg; Pfizer Animal Health).

\section{Clinical examinations and adverse event reporting}

The puppies underwent physical examination before the start of the trial and every 4 weeks thereafter. Particular attention was paid to signs of joint or muscle pain. In addition, any illness or injury 
Table 2. Population demographics of dogs completing the trial ${ }^{\star}$

\begin{tabular}{lcccc}
\hline & Group A & Group B & Group C & Group D \\
\hline$n$ & 15 & 11 & 11 & 11 \\
Breed & & 6 & 6 & 5 \\
$\quad$ MS & 8 & 5 & 6 & 6 \\
LR & 7 & 5 & 6 & 6 \\
Sex & & 6 & 6 & 5 \\
$\quad$ Male & 8 & 7 & & \\
Female & 7 & & \\
\hline
\end{tabular}

MS, Miniature Schnauzer; LR, Labrador Retriever.

* Group A, 5.24 $\mu \mathrm{mol}$ retinol (5000 IU vitamin A) $/ 4184 \mathrm{~kJ}(1000 \mathrm{kcal})$ metabolisable energy (ME); group B, $13.10 \mu \mathrm{mol}$ retinol (12500 IU vitamin A)/4184 kJ (1000 kcal) ME; group C, $78.60 \mu \mathrm{mol}$ retinol $(75000 \mathrm{IU}$ vitamin A)/4184 kJ (1000 kcal) ME; group D, $104.80 \mu \mathrm{mol}$ retinol (100 $000 \mathrm{IU}$ vitamin A)/4184 kJ (1000 kcal) ME.

between the examinations that required veterinary attention was considered an adverse event. Adverse events were classified into ten categories, namely: poor faeces quality, vomiting, foreign body ingestion, lameness, accident/injury, skin conditions, eye conditions, ear conditions, dental conditions and urinary conditions. On each occasion, the type and duration of treatment were recorded. Any blood parameters outside of the puppy reference range ${ }^{(18)}$ were referred to the veterinarian for investigation and re-tests were conducted within $24 \mathrm{~h}$ and repeated as required for diagnosis. The veterinarian was blinded to the dietary treatment groups.

\section{Data analysis and statistics}

The primary outcome variable was total serum retinyl ester concentration. Retinyl ester concentration was selected as the primary outcome variable to demonstrate a biological impact of feeding various levels of retinol to growing dogs. The study was powered at $90 \%$ to detect differences between the groups based on a previously described log-linear relationship between dietary vitamin $\mathrm{A}$ intake and serum retinyl ester concentration ${ }^{(3)}$. The power calculation determined a minimum of nine dogs per group; this was increased to eleven to account for potentially greater variability in puppies compared with adult dogs. Following the conclusion of the study, post hoc power analyses were conducted on each of the safety biomarkers to determine whether there was sufficient power $(>80 \%)$ to detect a clinically relevant effect size with the variation associated with the dataset. A clinically relevant change was defined as a change from the mean of each variable to a mean outside the reference range ${ }^{(18)}$.

Data were analysed by means of linear mixed model analysis including the fixed terms sample number, sex, breed and dietary group, and also the baseline measurement of the variable being modelled. The model included the random terms dog and litter (to take account of possible similarities between littermates), with a correlation between successive samples (within an individual dog) accounted for via use

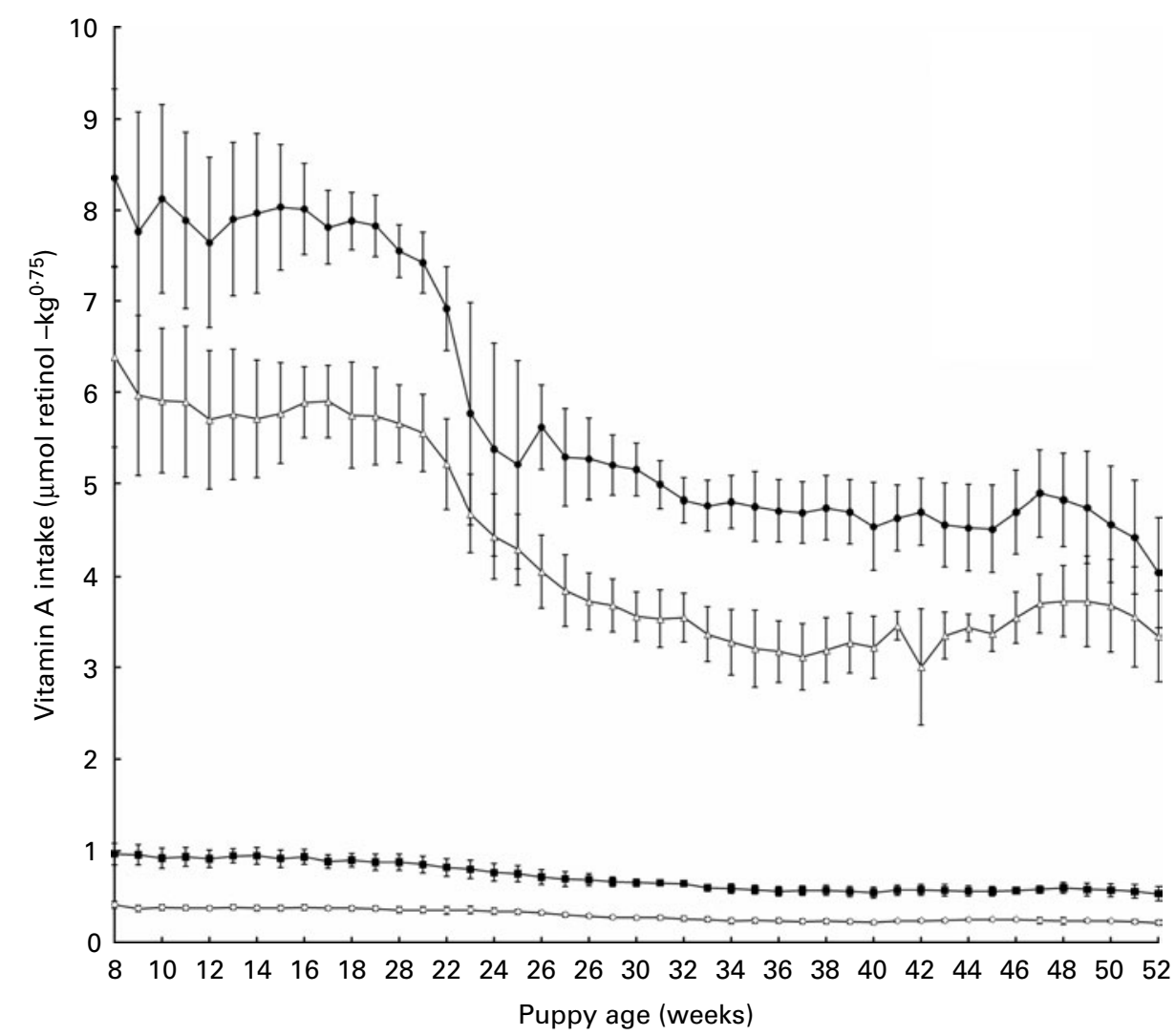

Fig. 1. Actual vitamin A intake of puppies from 8 to 52 weeks of age. Values are means, with $95 \% \mathrm{Cl}$ represented by vertical bars. Mean values were significantly different between the groups $(P<0.05)$. Group A $(\neg-), 5.24 \mu \mathrm{mol}$ retinol (5000 IU vitamin A)/4184kJ (1000 kcal) metabolisable energy (ME); group B $(\neg-)$, $13.10 \mu \mathrm{mol}$ retinol $(12500 \mathrm{IU}$ vitamin A)/4184 kJ (1000 kcal) ME; group C $(-\triangle)$ ), $78.60 \mu \mathrm{mol}$ retinol $(75000 \mathrm{IU}$ vitamin A)/4184 kJ (1000 kcal) ME; group D $(--), 104.80 \mu \mathrm{mol}$ retinol (100000 IU vitamin A)/4184 kJ (1000 kcal) ME. 


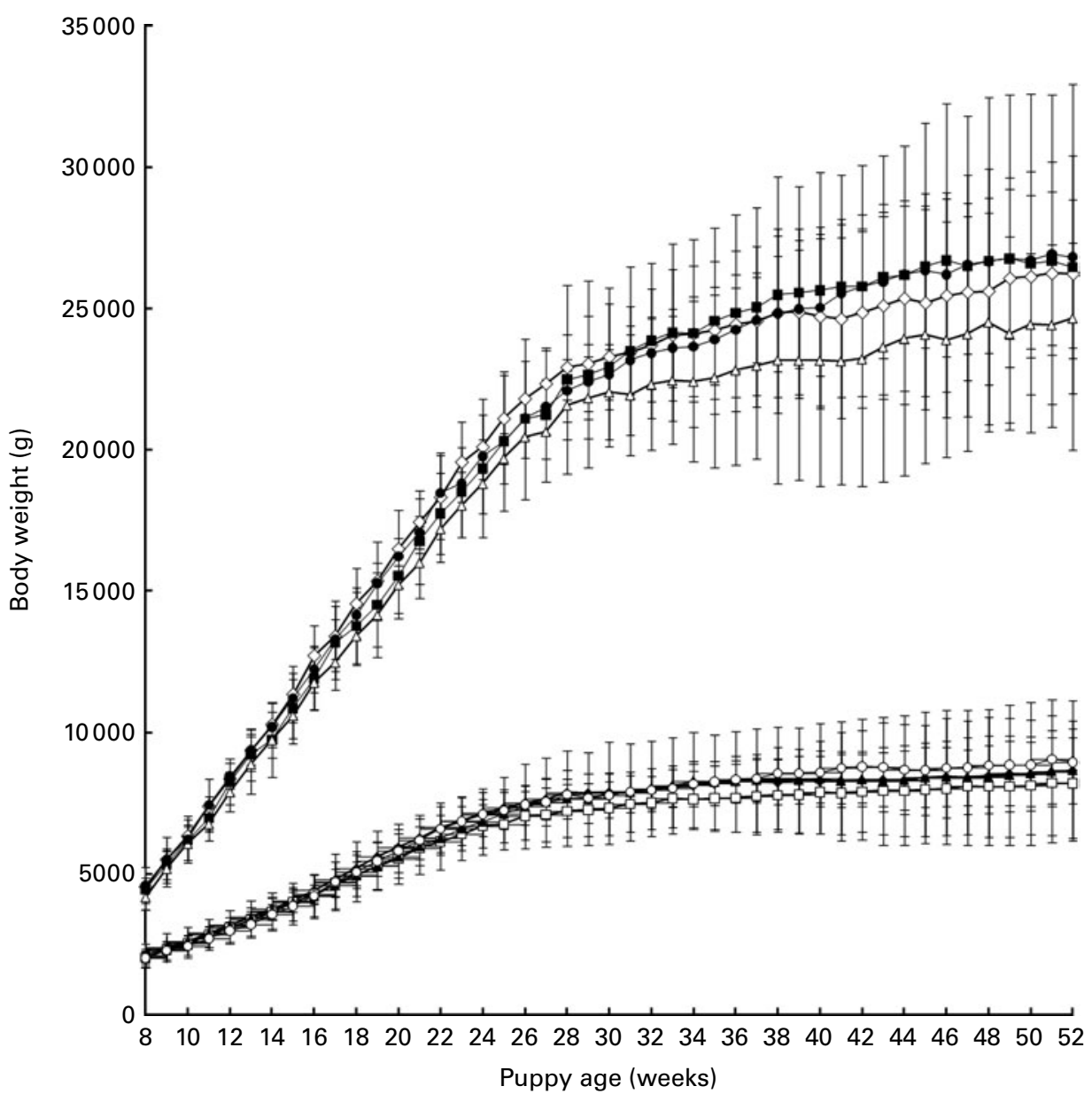

Fig. 2. Body weight of two breeds of puppies from 8 to 52 weeks of age. Values are means, with $95 \% \mathrm{Cl}$ represented by vertical bars. Mean values were significantly different between the groups $(P<0.05)$. Group A, $5.24 \mu \mathrm{mol}$ retinol (5000 IU vitamin A)/4184 kJ (1000 kcal) metabolisable energy (ME); group B, $13.10 \mu \mathrm{mol}$ retinol $(12500 \mathrm{IU}$ vitamin A)/4184 kJ (1000 kcal) ME; group C, $78.60 \mu \mathrm{mol}$ retinol (75000 IU vitamin A)/4184 kJ (1000 kcal) ME; group D, $104.80 \mu \mathrm{mol}$ retinol (100 $000 \mathrm{IU}$ vita-

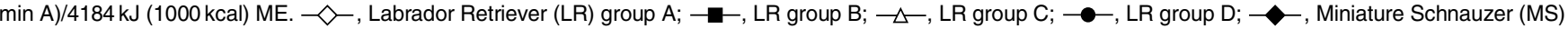
group $\mathrm{A} ;-\square$, MS group $\mathrm{B} ;-\_$, MS group $\mathrm{C} ;-\circ-$, MS group $\mathrm{D}$.

of an appropriate correlation structure (determined using graphical methods of residuals from a model with identity correlation structure). Where necessary, data were $\log _{e}$ transformed to improve the distribution of the data, as assessed by residual plots. Non-significant terms were removed from the model. Data analyses were performed using R.2.10.1 (R Foundation for Statistical Computing).

All primary and secondary endpoints were separately subjected to Bonferroni correction to account for the presence of multiple endpoints; the overall significance level used was 0.05. Data are presented as means with their $95 \%$ CI unless otherwise stated, and $P$ values are reported as Bonferroni-corrected $P$ values.

\section{Results}

\section{Population demographics}

The study population demographics are described in Table 2. A total of forty-eight dogs completed the study. A total of fortyeight dogs completed the study. A single LR, allocated to group C, was removed from the study at 9 months of age following diagnosis of a congenital kidney defect. All data from this dog were removed from the analysis. There were no differences in breed or sex distribution between the groups.

\section{Dietary intake and growth}

There were no significant differences in energy intake on a per $\mathrm{kg}$ body weight or per $\mathrm{kg}$ metabolic body-weight basis between the groups. As intended, there were significant differences in dietary vitamin A intake between the groups $(P=0.0001)$. When expressed on a per $\mathrm{kg}$ body-weight basis $(P=0.0001)$ and on a per $\mathrm{kg}$ metabolic body-weight basis ( $P=0.0001$ ) (Fig. 1), both vitamin A and energy intake significantly decreased over time with maximal intake recorded at week 8 . Body weight significantly increased in all groups with time ( $P=0 \cdot 0001$; Fig. 2$)$, and all dogs maintained an ideal body condition score (score D) throughout the trial. There were no significant differences in body weight between the groups at any time point $(P=1 \cdot 00)$ nor any significant differences in the rate of growth $(P=1 \cdot 00)$. There was a significant effect of breed, with LR having significantly higher body weights than MS $(P=0 \cdot 0008)$. 
Table 3. Change in clinical chemistry parameters with age and treatment group*

(Mean values with their $95 \%$ confidence intervals)

\begin{tabular}{|c|c|c|c|c|c|c|c|c|c|c|}
\hline & \multirow[b]{2}{*}{ Age (weeks) } & \multicolumn{2}{|c|}{ Group A† } & \multicolumn{2}{|c|}{ Group Bł } & \multicolumn{2}{|c|}{ Group C§ } & \multicolumn{2}{|c|}{ Group D\| } & \multirow[b]{2}{*}{$P q$} \\
\hline & & Mean & $95 \% \mathrm{Cl}$ & Mean & $95 \% \mathrm{Cl}$ & Mean & $95 \% \mathrm{Cl}$ & Mean & $95 \% \mathrm{Cl}$ & \\
\hline \multirow[t]{3}{*}{ Protein (g/l) } & 8 & $48 \cdot 3$ & $47 \cdot 2,49 \cdot 4$ & $49 \cdot 5$ & $47 \cdot 7,51 \cdot 3$ & $48 \cdot 3$ & $46 \cdot 4,50 \cdot 1$ & $47 \cdot 9$ & $46 \cdot 3,49 \cdot 5$ & \\
\hline & 26 & $55 \cdot 7$ & $53.9,57.5$ & $55 \cdot 8$ & $53 \cdot 3,58 \cdot 3$ & $55 \cdot 7$ & $54.0,57.5$ & $55 \cdot 5$ & $53 \cdot 8,57 \cdot 2$ & 0.526 \\
\hline & 52 & 54.9 & $53 \cdot 1,56 \cdot 6$ & $57 \cdot 3$ & $55 \cdot 3,59 \cdot 3$ & $58 \cdot 0$ & $56.5,59.5$ & $57 \cdot 1$ & $55 \cdot 4,58 \cdot 8$ & \\
\hline \multirow[t]{3}{*}{ Albumin (g/l) } & 8 & 24.9 & $23 \cdot 7,26 \cdot 1$ & $25 \cdot 1$ & $22 \cdot 9,27 \cdot 2$ & $24 \cdot 7$ & $22 \cdot 8,26 \cdot 6$ & $24 \cdot 0$ & $22 \cdot 3,25 \cdot 7$ & \\
\hline & 26 & $29 \cdot 6$ & $28 \cdot 9,30 \cdot 3$ & $29 \cdot 6$ & $28 \cdot 3,31 \cdot 0$ & $29 \cdot 1$ & $28 \cdot 2,30 \cdot 0$ & $29 \cdot 2$ & $28 \cdot 1,30 \cdot 2$ & 0.379 \\
\hline & 52 & $28 \cdot 5$ & $27 \cdot 1,29 \cdot 8$ & $29 \cdot 8$ & $28 \cdot 5,31 \cdot 1$ & $30 \cdot 3$ & $29 \cdot 2,31 \cdot 4$ & $29 \cdot 6$ & $28 \cdot 4,30.92$ & \\
\hline \multirow[t]{3}{*}{ Phosphate (mmol/l) } & 8 & $2 \cdot 72$ & $2 \cdot 63,2 \cdot 8$ & 2.69 & $2 \cdot 62,2 \cdot 75$ & $2 \cdot 71$ & $2 \cdot 58,2.84$ & $2 \cdot 72$ & $2 \cdot 61,2 \cdot 83$ & \\
\hline & 26 & $2 \cdot 29$ & $2 \cdot 12,2.45$ & $2 \cdot 24$ & $2.02,2.47$ & $2 \cdot 24$ & $2 \cdot 06,2.43$ & $2 \cdot 31$ & $2 \cdot 13,2 \cdot 48$ & 0.869 \\
\hline & 52 & $1 \cdot 64$ & $1 \cdot 54,1 \cdot 75$ & 1.63 & $1.52,1 \cdot 75$ & $1 \cdot 72$ & $1.58,1.86$ & 1.62 & $1 \cdot 5,1 \cdot 75$ & \\
\hline \multirow{3}{*}{ ALP (U/I) } & 8 & 432 & 405,460 & 447 & 396, 499 & 448 & 403,492 & 405 & 348,462 & \\
\hline & 26 & 221 & 187,254 & 232 & 210,255 & 247 & 213,281 & 222 & 189,256 & 0.780 \\
\hline & 52 & 104 & 76,132 & 103 & 83,124 & 109 & 86,132 & 109 & 82,137 & \\
\hline \multirow[t]{3}{*}{ ALT (U/I) } & 8 & $25 \cdot 6$ & $22 \cdot 5,28 \cdot 7$ & $25 \cdot 0$ & $20 \cdot 9,29 \cdot 2$ & $23 \cdot 8$ & $20 \cdot 7,27 \cdot 0$ & 23.9 & $19 \cdot 4,28 \cdot 4$ & \\
\hline & 26 & $37 \cdot 8$ & $34 \cdot 5,41 \cdot 1$ & $42 \cdot 7$ & $35 \cdot 1,50 \cdot 4$ & $35 \cdot 1$ & $31 \cdot 7,38 \cdot 5$ & $41 \cdot 3$ & $34 \cdot 8,47 \cdot 8$ & 0.862 \\
\hline & 52 & $48 \cdot 5$ & $34 \cdot 5,62 \cdot 6$ & $45 \cdot 7$ & $39 \cdot 0,52 \cdot 4$ & $39 \cdot 0$ & $34 \cdot 9,43 \cdot 1$ & $63 \cdot 1$ & $33 \cdot 7,92 \cdot 6$ & \\
\hline \multirow[t]{3}{*}{ AST (U/I) } & 8 & 24.9 & $21 \cdot 5,28 \cdot 3$ & $23 \cdot 3$ & $20 \cdot 7,25 \cdot 9$ & $24 \cdot 9$ & $21 \cdot 9,27 \cdot 9$ & $24 \cdot 6$ & $22 \cdot 0,27 \cdot 3$ & \\
\hline & 26 & $30 \cdot 5$ & $27 \cdot 4,33 \cdot 6$ & $29 \cdot 2$ & $25 \cdot 6,32 \cdot 9$ & $29 \cdot 3$ & $25 \cdot 8,32 \cdot 8$ & $30 \cdot 7$ & $25 \cdot 2,36 \cdot 1$ & 0.695 \\
\hline & 52 & $30 \cdot 0$ & $27 \cdot 0,33 \cdot 0$ & $29 \cdot 3$ & $25 \cdot 6,32 \cdot 9$ & $28 \cdot 1$ & $25 \cdot 8,30.5$ & $27 \cdot 5$ & $23 \cdot 6,31 \cdot 4$ & \\
\hline \multirow[t]{3}{*}{$\mathrm{Ca}(\mathrm{mmol} / \mathrm{l})$} & 8 & $2 \cdot 84$ & $2 \cdot 80,2 \cdot 88$ & $2 \cdot 84$ & $2.79,2.89$ & $2 \cdot 82$ & $2 \cdot 76,2 \cdot 87$ & 2.83 & $2 \cdot 79,2 \cdot 87$ & \\
\hline & 26 & $2 \cdot 75$ & $2 \cdot 71,2 \cdot 80$ & 2.79 & $2 \cdot 75,2 \cdot 84$ & 2.77 & $2 \cdot 72,2 \cdot 82$ & 2.77 & $2 \cdot 72,2 \cdot 82$ & 0.535 \\
\hline & 52 & 2.59 & $2.55,2.63$ & $2 \cdot 62$ & $2.59,2.64$ & 2.65 & $2 \cdot 60,2 \cdot 71$ & $2 \cdot 60$ & $2 \cdot 56,2.64$ & \\
\hline \multirow[t]{3}{*}{ Cholesterol (mmol/l) } & 8 & $5 \cdot 18$ & $4.78,5.58$ & $5 \cdot 02$ & $4 \cdot 62,5 \cdot 42$ & 4.87 & $4 \cdot 45,5 \cdot 29$ & 4.96 & $4 \cdot 58,5 \cdot 33$ & \\
\hline & 26 & $7 \cdot 00$ & $6 \cdot 33,7 \cdot 67$ & 6.84 & $6.15,7.52$ & 6.53 & $5 \cdot 86,7 \cdot 2$ & 6.79 & $6 \cdot 25,7 \cdot 32$ & 0.974 \\
\hline & 52 & $5 \cdot 86$ & $5 \cdot 21,6 \cdot 51$ & $6 \cdot 11$ & $5 \cdot 54,6 \cdot 67$ & $5 \cdot 86$ & $5 \cdot 27,6 \cdot 46$ & $6 \cdot 14$ & $5 \cdot 61,6 \cdot 66$ & \\
\hline \multirow[t]{3}{*}{ Urea (mmol/l) } & 8 & $2 \cdot 29$ & $2.03,2.55$ & 2.39 & $2 \cdot 04,2 \cdot 75$ & 2.56 & $2 \cdot 19,2.94$ & $2 \cdot 17$ & $1.97,2.37$ & \\
\hline & 26 & 4.96 & $4.49,5.43$ & 4.91 & $4 \cdot 44,5 \cdot 39$ & $4 \cdot 81$ & $4 \cdot 47,5 \cdot 13$ & 4.57 & $4 \cdot 19,4.94$ & 0.135 \\
\hline & 52 & $5 \cdot 74$ & $5 \cdot 35,6 \cdot 13$ & $5 \cdot 78$ & $5 \cdot 35,6 \cdot 22$ & 6.00 & $5 \cdot 35,6 \cdot 64$ & 5.44 & $4 \cdot 84,6 \cdot 04$ & \\
\hline \multirow[t]{3}{*}{ Creatinine $(\mathrm{mmol} / \mathrm{l})$} & 8 & $38 \cdot 3$ & $36 \cdot 9,39 \cdot 6$ & $38 \cdot 0$ & $36 \cdot 3,39 \cdot 7$ & $36 \cdot 5$ & $35 \cdot 0,38 \cdot 0$ & $37 \cdot 9$ & $36 \cdot 7,39 \cdot 3$ & \\
\hline & 26 & $72 \cdot 3$ & $68 \cdot 7,76 \cdot 0$ & $70 \cdot 3$ & $68 \cdot 2,72 \cdot 5$ & $67 \cdot 7$ & $65 \cdot 3,70 \cdot 2$ & $69 \cdot 8$ & $65 \cdot 6,73.9$ & 0.500 \\
\hline & 52 & $83 \cdot 1$ & $76.4,89.9$ & $84 \cdot 9$ & $77 \cdot 5,92 \cdot 2$ & $83 \cdot 6$ & $77 \cdot 1,90 \cdot 1$ & $82 \cdot 7$ & $75 \cdot 3,90 \cdot 0$ & \\
\hline \multirow[t]{3}{*}{ TAG $(\mathrm{mmol} / \mathrm{l})$} & 8 & 0.68 & $0 \cdot 6,0.76$ & 0.67 & $0.6,0.75$ & 0.62 & $0.53,0.71$ & 0.61 & $0.54,0.68$ & \\
\hline & 26 & 0.71 & $0.56,0.85$ & 1.03 & $0.45,1.62$ & 0.72 & $0.52,0.91$ & 0.65 & $0.52,0.77$ & 0.661 \\
\hline & 52 & 0.54 & $0.46,0.62$ & 0.59 & $0.43,0.74$ & 0.57 & $0.49,0.65$ & 0.71 & $0.55,0.87$ & \\
\hline \multirow[t]{3}{*}{ Total bile acids $(\mu \mathrm{mol} / \mathrm{l})$} & 8 & 2.65 & $1 \cdot 18,4 \cdot 12$ & $3 \cdot 11$ & $0.33,5.88$ & 3.65 & $1 \cdot 2,6 \cdot 11$ & 1.65 & $1.3,1.99$ & \\
\hline & 26 & $3 \cdot 18$ & $1 \cdot 64,4.72$ & 5.55 & $2 \cdot 77,8 \cdot 32$ & $1 \cdot 30$ & $1.05,1.56$ & $2 \cdot 40$ & $0.83,3.96$ & 0.759 \\
\hline & 52 & $4 \cdot 22$ & $1 \cdot 22,7 \cdot 23$ & $7 \cdot 03$ & $0.39,13.66$ & $7 \cdot 37$ & $1 \cdot 38,13 \cdot 36$ & 2.92 & $1.53,4.32$ & \\
\hline \multirow[t]{3}{*}{ GLDH (U/I) } & 8 & $4 \cdot 67$ & $4 \cdot 31,5 \cdot 04$ & $4 \cdot 54$ & $4 \cdot 19,4 \cdot 90$ & $4 \cdot 40$ & $3.87,4.92$ & $4 \cdot 62$ & $4 \cdot 19,5 \cdot 06$ & \\
\hline & 26 & $5 \cdot 23$ & $4.50,5.95$ & 6.41 & $4.79,8.04$ & $4 \cdot 70$ & $4 \cdot 12,5 \cdot 28$ & $5 \cdot 41$ & $4 \cdot 34,6 \cdot 48$ & 0.355 \\
\hline & 52 & 6.45 & $3 \cdot 74,9 \cdot 15$ & $5 \cdot 10$ & $4 \cdot 02,6 \cdot 19$ & 4.85 & $3 \cdot 72,5 \cdot 98$ & $5 \cdot 86$ & $3.98,7 \cdot 73$ & \\
\hline \multirow[t]{3}{*}{ bALP (pmol/l) } & 8 & $87 \cdot 9$ & $81 \cdot 7,94 \cdot 1$ & $94 \cdot 1$ & $78 \cdot 5,109 \cdot 8$ & $88 \cdot 7$ & $76 \cdot 7,100 \cdot 7$ & $80 \cdot 0$ & $69 \cdot 2,90 \cdot 8$ & \\
\hline & 26 & $40 \cdot 7$ & $35 \cdot 3,46 \cdot 1$ & $43 \cdot 0$ & $38 \cdot 3,47 \cdot 6$ & $44 \cdot 1$ & $39 \cdot 1,49 \cdot 0$ & $38 \cdot 3$ & $33 \cdot 2,43 \cdot 3$ & 1.00 \\
\hline & 52 & $15 \cdot 9$ & $12 \cdot 0,19 \cdot 8$ & $15 \cdot 6$ & $12 \cdot 3,18 \cdot 9$ & $16 \cdot 3$ & $12 \cdot 8,19 \cdot 9$ & $15 \cdot 5$ & $11 \cdot 8,19 \cdot 1$ & \\
\hline CTx (pg/ml) & 8 & 294 & 250,338 & 324 & 255, 393 & 289 & 236,342 & 333.1 & 277, 389 & \\
\hline & 26 & 646 & 547,745 & 651 & 544,759 & 605 & 521,689 & 595 & 498,692 & 1.00 \\
\hline & 52 & 915 & 740,1089 & 915 & 740,1088 & 821 & 637,1006 & 878 & 647,1110 & \\
\hline
\end{tabular}

ALP, alkaline phosphatase; ALT, alanine aminotransferase; AST, aspartate aminotransferase; GLDH, glutamate dehydrogenase; bALP, bone-specific ALP; CTx, carboxyterminal telopeptides of type I collagen.

* Data were analysed via mixed model.

†5.24 $\mu \mathrm{mol}$ retinol ( $5000 \mathrm{IU}$ vitamin A)/4184 kJ (1000 kcal) metabolisable energy (ME).

$\$ 13.10 \mu \mathrm{mol}$ retinol (12500 IU vitamin A) $/ 4184 \mathrm{~kJ}$ (1000 kcal) ME.

$\$ 78.60 \mu \mathrm{mol}$ retinol $(75000 \mathrm{IU}$ vitamin A) $/ 4184 \mathrm{~kJ}(1000 \mathrm{kcal}) \mathrm{ME}$.

|| $104.80 \mu \mathrm{mol}$ retinol (100 $000 \mathrm{lU}$ vitamin A)/4184 kJ (1000 kcal) ME.

I Significance of difference between the treatment groups (Bonferroni corrected).

\section{Blood sample analysis}

There were no significant differences in any of the haematological or biochemical parameters between the groups at any time point. However, some variables (Table 3), namely erythrocyte count, mean corpuscular volume, mean corpuscular $\mathrm{Hb}$, mean corpuscular $\mathrm{Hb}$ concentration, mean platelet volume, number of monocytes, number of granulocytes,

alanine aminotransferase, aspartate aminotransferase, alkaline phosphatase and cholesterol, showed statistically significant changes with age. Bone-specific alkaline phosphatase significantly decreased $(P=0 \cdot 0001)$ and cross-laps (CTx) significantly increased $(P=0.0001)$ with age. There were no significant differences, however, in the concentrations of bone-specific alkaline phosphatase $(P=1.00)$ or CTx $(P=1.00)$ between any of the groups at any time point. 


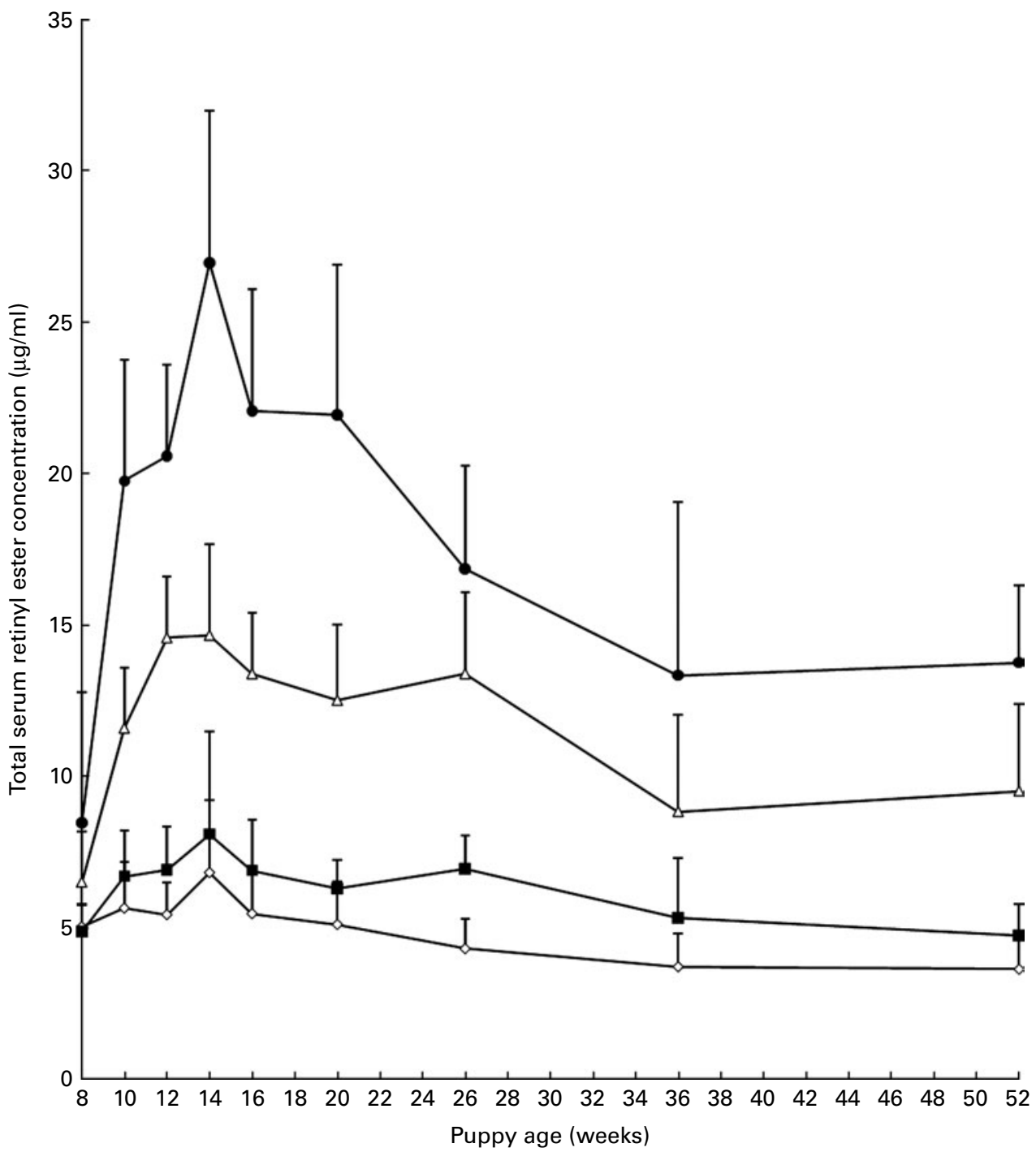

Fig. 3. Change in total serum retinyl ester concentrations with age in growing puppies. Values are means, with $95 \% \mathrm{Cl}$ represented by vertical bars. Mean values were significantly different between the groups $(P<0.05)$. Group A $(\checkmark-), 5.24 \mu \mathrm{mol}$ retinol (5000 IU vitamin A)/4184 kJ (1000 kcal) metabolisable energy (ME); group B (- $(-), 13.10 \mu \mathrm{mol}$ retinol (12500 IU vitamin A)/4184 kJ (1000 kcal) ME; group C $(\neg-), 78.60 \mu \mathrm{mol}$ retinol $(75000 \mathrm{IU}$ vitamin A)/4184kJ $(1000 \mathrm{kcal})$ ME; group D (־-), $104.80 \mu \mathrm{mol}$ retinol (100 000 IU vitamin A)/4184 kJ (1000 kcal) ME.

Both serum retinol $(P=0 \cdot 0001)$ and serum total retinyl ester concentrations $(P=0 \cdot 015)$ increased with time. There was no significant difference in serum retinol concentration between the groups $(P=1 \cdot 00)$, whereas total retinyl ester concentrations were significantly different (Fig. 3) between each group and all the other groups at all time points $(P=0.0001)$ with the exception of baseline (week 8).

\section{Urine sample analysis}

Excretion of retinol and retinyl esters in the urine was negligible up to 26 weeks of age and was not consistently detected until 35 weeks of age (Fig. 4). There were no significant differences in the time to excretion of retinol $(P=1 \cdot 00)$ or retinyl esters $(P=1.00)$ between the groups nor were there differences between the groups in concentrations of retinol $(P=1.00)$ and retinyl esters $(P=1.00)$ excreted at weeks 35 and 52

\section{Bone mineral density and bone mineral content}

There was no significant effect of dietary vitamin A concentration on BMD $(P=0 \cdot 137)$ or bone mineral content $(P=0.936)$ as assessed by DXA (Table 4 ). There was a significant effect of breed, with LR having greater BMD $(P=0.0001)$ and bone mineral content $(P=0 \cdot 0020)$ than MS at both time points.

\section{Clinical examination and adverse events}

There were no significant differences between the treatment groups in the number and type of adverse events reported. Poor faeces quality was the most commonly reported adverse event ( $n$ 22), with twenty individual dogs affected. All cases were resolved within $3 \mathrm{~d}$. In LR, two cases of lameness without apparent cause were observed, one in group A and one in group $\mathrm{C}$; both cases were resolved following treatment in less than $7 \mathrm{~d}$. 


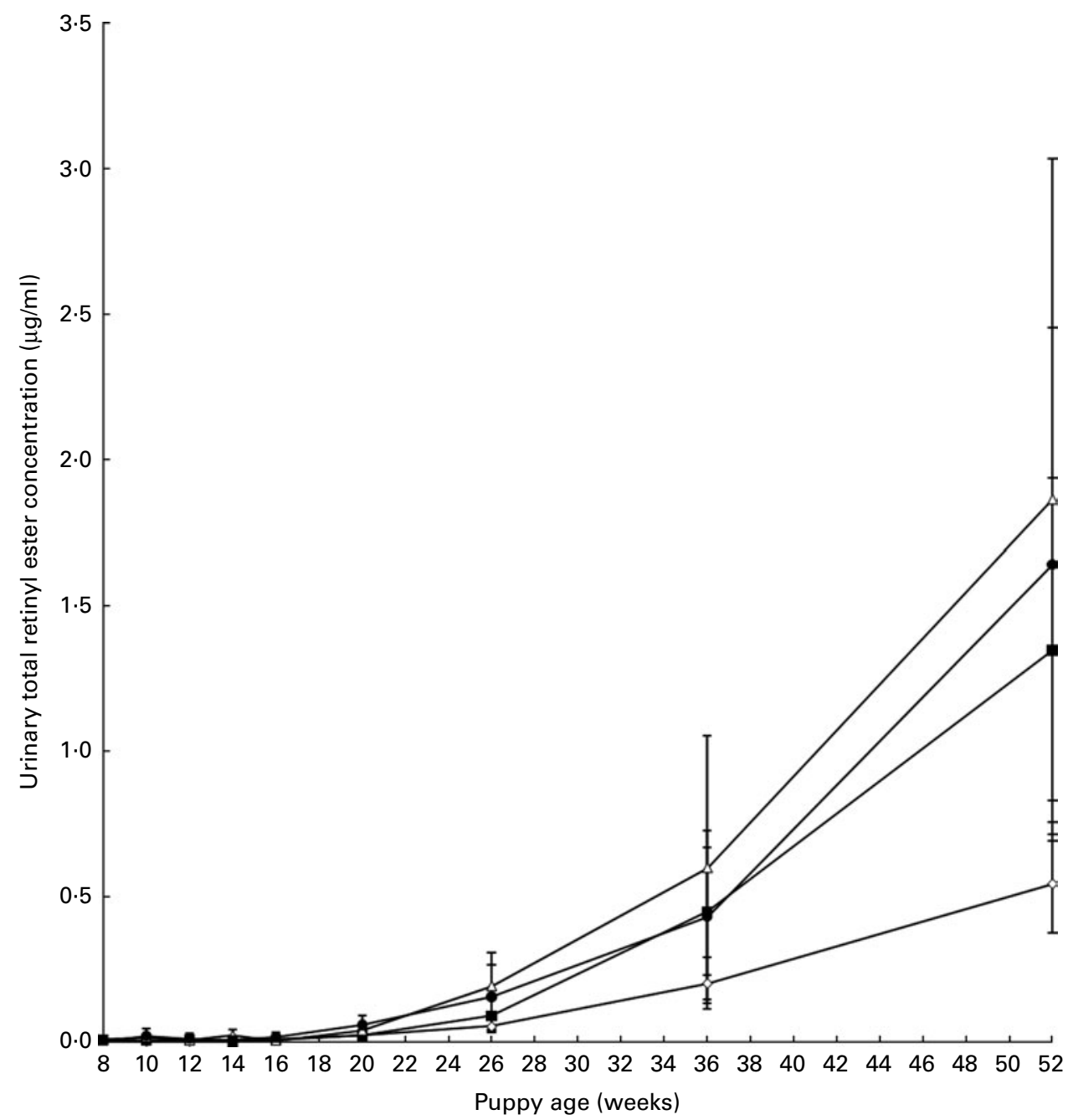

Fig. 4. Total urinary retinyl ester excretion. Values are means, with $95 \% \mathrm{Cl}$ represented by vertical bars. Mean values were significantly different between the groups $(P<0.05)$. Group A $(\checkmark-), 5.24 \mu \mathrm{mol}$ retinol $(5000 \mathrm{IU}$ vitamin A)/4184 kJ (1000 kcal) metabolisable energy (ME); group B $(--), 13.10 \mu \mathrm{mol}$ retinol $(12500 \mathrm{IU}$ vitamin A)/4184 kJ (1000 kcal) ME; group C ( $\neg), 78.60 \mu \mathrm{mol}$ retinol $(75000 \mathrm{IU}$ vitamin A)/4184 kJ (1000 kcal) ME; group D ( $\bullet-), 104.80 \mu \mathrm{mol}$ retinol (100000 IU vitamin A)/4184 kJ (1000 kcal) ME.

\section{Discussion}

The hypothesis tested was that feeding dietary vitamin A at concentrations up to $104 \cdot 80 \mu \mathrm{mol}$ retinol (100000 IU vitamin A)/4184 kJ (1000 kcal) ME to puppies during growth would not result in any significant changes in biomarkers associated with health.

No significant differences were found in any of the biomarkers of health including biochemical markers or haematological parameters. Previous data from human subjects and other animal species indicate that excess vitamin A is associated with a stimulation of bone resorption and an inhibition of bone formation leading to a reduction in BMD potentially resulting from interactions between vitamins $A$ and $D^{(11)}$. No significant differences were found in the biomarkers of these processes namely bone-specific alkaline phosphatase and CTx, and there was no significant effect of dose on either BMD or bone mineral content as assessed by DXA. There are no specific studies examining the interaction between vitamins $\mathrm{A}$ and $\mathrm{D}$ in the dog. In rats and broiler chickens, biochemical studies have suggested an antagonism between vitamins A and D at the receptor level ${ }^{(19,20)}$ as well as an interaction with Ca-regulating hormones such as parathyroid hormone ${ }^{(21)}$. There was no significant effect of dietary vitamin A concentration on plasma $\mathrm{Ca}$ or $\mathrm{P}$ levels, which suggests that vitamin D deficiency did not occur, although the levels of cholecalciferol in the diet were approximately three times the FEDIAF's recommended allowance ${ }^{(15)}$. Further studies are required to understand whether there is an interaction between vitamins $\mathrm{A}$ and $\mathrm{D}$ in the dog and if so, at which dietary concentrations an interaction occurs.

Feeding high levels of retinol has also been shown to prolong activated prothrombin time in the dog, although not outwith the reference range ${ }^{(1)}$. This is potentially due to the interactions with vitamin $\mathrm{K}$. Activated prothrombin time was not directly measured in the present study; however, no signs of clinical vitamin $\mathrm{K}$ deficiency such as increased bleeding tendency were observed. 
Table 4. Changes in bone mineral density (BMD) and bone mineral content (BMC) with age in puppies

(Mean values with their $95 \%$ confidence intervals)

\begin{tabular}{|c|c|c|c|c|c|c|c|c|c|c|c|}
\hline \multirow[b]{2}{*}{ Measure } & \multirow{2}{*}{$\begin{array}{c}\text { Age } \\
\text { (weeks) }\end{array}$} & \multirow[b]{2}{*}{ Breed } & \multicolumn{2}{|c|}{ Group A† } & \multicolumn{2}{|c|}{ Group B $\ddagger$} & \multicolumn{2}{|c|}{ Group C§ } & \multicolumn{2}{|c|}{ Group D\| } & \multirow[b]{2}{*}{$P \|$} \\
\hline & & & Mean & $95 \% \mathrm{Cl}$ & Mean & $95 \% \mathrm{Cl}$ & Mean & $95 \% \mathrm{Cl}$ & Mean & $95 \% \mathrm{Cl}$ & \\
\hline \multirow[t]{4}{*}{$\mathrm{BMD}\left(\mathrm{g} / \mathrm{cm}^{2}\right)$} & \multirow[t]{2}{*}{26} & MS & 0.69 & $0.68,0.71$ & 0.69 & $0.68,0.70$ & 0.70 & $0.69,0.71$ & 0.71 & $0.68,0.74$ & \multirow[t]{4}{*}{0.137} \\
\hline & & LR & 0.86 & $0.84,0.87$ & 0.86 & $0.82,0.90$ & 0.92 & $0.79,1.06$ & 0.86 & $0.84,0.87$ & \\
\hline & \multirow[t]{2}{*}{52} & MS & 0.72 & $0.70,0.73$ & 0.71 & $0.69,0.73$ & 0.73 & $0.72,0.75$ & 0.74 & $0.72,0.77$ & \\
\hline & & LR & 0.94 & $0.92,0.95$ & 0.94 & $0.89,1.00$ & 0.91 & $0.86,0.95$ & 0.94 & $0.90,0.99$ & \\
\hline \multirow[t]{4}{*}{ BMC (g) } & \multirow[t]{2}{*}{26} & MS & 179.5 & $166.0,193.0$ & $168 \cdot 1$ & $155 \cdot 0,181 \cdot 1$ & 179.8 & $155 \cdot 7,156 \cdot 2$ & 178.5 & $156 \cdot 2,200 \cdot 8$ & \multirow[t]{4}{*}{0.936} \\
\hline & & LR & 677.4 & $640 \cdot 7,714 \cdot 1$ & 654.7 & $553 \cdot 6,755 \cdot 8$ & 699.4 & $539 \cdot 1,859 \cdot 7$ & $660 \cdot 1$ & $611 \cdot 1,709 \cdot 1$ & \\
\hline & \multirow[t]{2}{*}{52} & MS & $211 \cdot 2$ & $193 \cdot 1,229 \cdot 2$ & 196.5 & $174 \cdot 3,218 \cdot 6$ & 214.7 & $178 \cdot 3,251 \cdot 1$ & $216 \cdot 8$ & $191 \cdot 2,242 \cdot 5$ & \\
\hline & & LR & $866 \cdot 8$ & $787 \cdot 6,946 \cdot 1$ & $887 \cdot 3$ & $721 \cdot 3,1053 \cdot 3$ & 774.4 & $711 \cdot 6,837 \cdot 2$ & 904.4 & $791 \cdot 0,1017 \cdot 8$ & \\
\hline
\end{tabular}

MS, Miniature Schnauzer; LR, Labrador Retriever.

${ }^{*}$ Data were analysed via mixed model.

†5.24 $\mu \mathrm{mol}$ retinol (5000 IU vitamin A)/4184 kJ (1000 kcal) metabolisable energy (ME).

$\ddagger 13.10 \mu \mathrm{mol}$ retinol (12500 IU vitamin A)/4184 kJ (1000 kcal) ME.

$\S 78.60 \mu \mathrm{mol}$ retinol (75000 IU vitamin A)/4184 kJ (1000 kcal) ME.

\| $104.80 \mu \mathrm{mol}$ retinol (10000 IU vitamin A)/4184 kJ (1000 kcal) ME.

I Significance of difference between the treatment groups (Bonferroni corrected).

Unlike previous studies in young dogs fed much higher dietary concentrations of vitamin A $(314.41 \mu \mathrm{mol}$ retinol (300000 IU vitamin A) $/ \mathrm{kg}$ body weight $)^{(9)}$, there were no differences in the rate of growth, energy intake or body weight at any time between the groups. No differences in the number, type or duration of adverse effects were observed and those that were observed could not be attributed to the variation in dietary vitamin A concentration. The present study was limited to the first 52 weeks of life and suggests that dietary vitamin A at the concentrations tested is safe to feed during this growth phase.

As with observations in adult $\operatorname{dogs}{ }^{(3)}$, increased dietary retinol concentration was associated with increased serum retinyl ester concentrations (Fig. 3) but not with serum retinol concentrations. Until 26 weeks of age, the concentrations of retinol observed in the present study were significantly lower than concentrations previously reported in adult $\operatorname{dogs}{ }^{(3)}$. This observation is consistent with previous reports of increasing concentrations of retinol in the serum of maned wolf cubs with age that reached adult concentrations at approximately 5 months of age $\mathrm{e}^{(22)}$

Unlike observations in adult dogs, however, the puppies excreted negligible amounts of retinol and retinol esters in the urine (Fig. 4). The excretion of these compounds appears to be age dependent rather than as a result of storage capacity, as there was no difference between the groups in time to excretion or total amounts of the compounds excreted despite a 20-fold difference in the doses fed. Previous research in adult $\operatorname{dogs}^{(4)}$ suggested that excess dietary vitamin $\mathrm{A}$ is stored in the stellate cells of the liver but in the present study, we were unable to confirm whether, and how, vitamin A was stored in the liver of puppies since this would have required serial liver biopsies to determine the effect of time. Liver biopsies were not included in the protocol due to the host institution's ethical policy. The lack of retinol and retinyl ester excretion in the urine until 35 weeks of age certainly requires further investigation. Examination of the proteins known to be involved in retinyl ester transport and excretion such as retinal-binding protein and Tamm-Horsfall-like protein $^{(23)}$ may provide an insight into the mechanism behind this age-dependent effect.

In summary, no adverse effects were detected with feeding dietary vitamin A at concentrations up to $104 \cdot 80 \mu \mathrm{mol}$ retinol (10000 IU vitamin A)/4184 kJ (1000 kcal) to MS and LR puppies from 8 weeks to 12 months of age. We therefore propose that $100000 \mathrm{IU}$ vitamin $\mathrm{A} / 4184 \mathrm{~kJ}(1000 \mathrm{kcal})$ is a suitable safe upper limit for use in the formulation of diets designed for puppy growth

\section{Acknowledgements}

This study was jointly funded by the FEDIAF and Mars PetCare $^{\mathrm{TM}}$. The authors wish to recognise Karen Holmes, Gaëlle Thomas and Amelia Wagstaff for their dedicated participation in the running of this study. All authors were involved in the design and oversight of the study. P. J. M. was responsible for the conduct of the study. J. R. and F. J. S. were responsible for the analysis of vitamin A metabolites and bone turnover markers. C. S. performed the statistical analyses. P. J. M. wrote the paper and all authors were responsible for the final manuscript. Conflicts of interest: P. J. M., C. S. and T. B. are employees of Mars PetCare ${ }^{\mathrm{TM}}$.

\section{References}

1. Goldy GG, Burr JR, Langardener CN, et al. (1996) Effects of measured doses of vitamin A fed to healthy beagle dogs for 26 weeks. Vet Clin Nutr 3, 42-49.

2. Wilson DE, Hejazi J, Elstad NL, et al. (1987) Novel aspects of vitamin A metabolism in the dog: distribution of lipoprotein retinyl esters in vitamin A-deprived and cholesterol-fed animals. Biochim Biophys Acta 922, 247-258.

3. Schweigert FJ \& Bok V (2000) Vitamin A in blood plasma and urine of dogs is affected by the dietary level of vitamin A. Int J Vitam Nutr Res 70, 84-91.

4. Raila J, Buchholz I, Aupperle H, et al. (2000) The distribution of vitamin A and retinol-binding protein in the blood plasma, urine, liver and kidneys of carnivores. Vet Res $\mathbf{3 1}$, 541-551. 
5. Lawrie NR, Moore T \& Rajagopal KR (1941) The excretion of vitamin A in urine. Biochem J 35, 825-836.

6. Worden AN, Bunyan J \& Davies AW (1954) The urinary excretion of vitamin A by the dog. Biochem J 59, 527-528.

7. Schweigert FJ, Thomann E \& Zucker H (1991) Vitamin A in the urine of carnivores. Int J Vitam Nutr Res 61, 110-113.

8. Frohring WO (1935) Vitamin A requirements of growing puppies. Proc Soc Exp Biol Med 33, 280-282.

9. Maddock CL, Wolbach SB \& Maddock S (1949) Hypervitaminosis A in the dog. J Nutr 39, 117-137.

10. Wiersig DO \& Swenson MJ (1967) Teratogenicity of vitamin A in the canine. Fed Proc 26, 486.

11. Cho DY, Frey RA, Guffy MM, et al. (1975) Hypervitaminosis A in the dog. AJVR 36, 1597-1603.

12. Hendricks JB, Morgan AF \& Freytag RM (1947) Chronic moderate hypervitaminosis D in young dogs. Am J Physiol 149, 314-332.

13. National Research Council (2006) Nutrient Requirements of Cats and Dogs, 1st ed. Washington DC: The National Academies Press.

14. American Association of Feed Control Officials (2011) American Association of Feed Control Officials Official Publication, 1st ed. Washington DC: Association of American Feed Control Officials Inc.

15. FEDIAF (2008) Nutritional Guidelines for Complete and Complimentary Pet Food for Cats and Dogs. Brussels: FEDIAF - European Pet Food Industry Federation.
16. Hawthorne AJ, Booles D, Nugent PA, et al. (2004) Bodyweight changes during growth of puppies of different breeds. J Nutr 134, 2027S-2030S.

17. German A, Holden SL, Moxham, et al. (2006) A simple reliable tool for owners to assess the body condition of their dog or cat. J Nutr 136, 2031S-2033S.

18. Harper EJ, Hackett RM, Wilkinson J, et al. (2003) Age-related variations in hematologic and plasma biochemical test results in Beagles and Labrador Retrievers. I Am Vet Med Assoc 223, 1436-1442

19. Rohde CM, Manatt M, Clagett-Dame M, et al. (1999) Vitamin A antagonises the action of vitamin D in rats. $J$ Nutr $\mathbf{1 2 9}$ 2246-2250.

20. Aburto A, Edwards HM \& Britton WM (1998) The influence of vitamin A on the utilisation and amerlioration of toxicity of cholecalciferol, 25-hydroxycholecalciferol in young broiler chickens. Poult Sci 77, 585-593.

21. Lui W, Hellman P, Li Q, et al. (1996) Biosynthesis and function of all-trans- and 9-cis-retinoic acid in parathyroid cells. Biochem Biophys Res Commun 229, 922-929.

22. Schweigert FJ, Ryder OA, Rambeck WA, et al. (1990) The majority of vitamin A is transported as retinyl esters in the blood of most carnivores. Comp Biochem Physiol 95, 573-578.

23. Schweigert FJ, Raila J \& Haebel S (2002) Vitamin A excreted in the urine of canines is associated with a Tamm-Horsfall like protein. Vet Res 33, 299-311. 